\title{
USING MINDFULNESS, AS THE METHOD OF SELF-REGULATION FOR CREATIVITY DEVELOPMENT
}

\author{
Gevorgyan A. Kh. (Public Administration Academy of the RA, Yerevan, Armenia) \\ astgh.gevorgyan@gmail.com

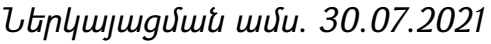 \\ 9pmpunuर्umध шर्रu. 09.08.2021

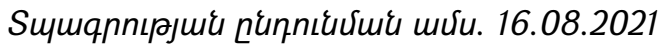

The objective of the study is to find out the influence of the mindfulness meditation on the development of creativity. The article describes how the mindfulness meditation can promote the development of creativity.

Survey, correlational and experimental research was done using the research methods of testing and experiment. The methods of diagnostics are the test by F. Williams for creativity assessment and Five Facet Mindfulness Questionnaire (FFMQ) by Ruth Baer. The correlational research showed that there were considerable connections among the level of awareness and creativity. As a result of the qualitative analyses of the experiment, it turned out that the solutions suggested by the students were more creative after the meditations. The results of the retesting showed that the level of the creativity has improved after the 5-days mindfulness training. The study opens new perspectives to manipulate with the mindfulness based interventions in order to receive more significant results for creativity development.

Keywords: mindfulness, meditation, creativity, self-regulation, training, development.

DOI: https://doi.org/10.46991/SBMP/2021.4.2.173

Entering the modern rapidly evolving and changing world, the young man has to make many decisions in a short period of time in different spheres of life and activity: education, personal life, career, self-realization. In order to be successful, these decisions must approach the problem from different angles, be unique and flexible and meet the requirements of the environment. At the same time, the mechanical work done by man is already automated today, as a result of which the creative mind is appreciated and used even more. It is not accidental that creative thinking was declared the primary quality required by employers in 2021. The development of creativity by using the psychological self-regulation methods, particularly mindfulness practices, has been less studied.

Examining the approaches of different authors on creativity and its development, we have taken the following theoretical basis for the research: 
Mednik's associative approach, M. Beeman and J Kounios's approach of general distant associations. In order to define the criteria for creativity development, we have taken D. Guilford's approach of divergent thinking, E. De Bono's approach of lateral thinking. For the personal qualities of a creative person and for their development we have taken the multifactor approach of $\mathrm{T}$. Lyubart and R. Sternberg. When studying the peculiarities of the development of creativity, we have taken into account the studies done by the Armenian scientists, S. Poghosyan, R . Aghuzumtsyan, D . Hayrapetyan. Studying the approaches of various authors on psychological self-regulation and its methods, we have chosen mindfulness meditation as a method of psychological self-regulation in the process of creativity development. As a basis for our research we have chosen the approaches of J. KabatZinn (mindfulness state) and D. Penman (creativity for mindfulness).

The objective of the study is to find out the influence of the mindfulness meditation on the development of creativity. The hypothesis is that mindfulness meditation, as a method of psychological self-regulation, has an influence on the development of creativity. The article describes how the mindfulness meditation can promote the development of creativity during incubation and insight, two stages of creative process. Creativity is the ability of a person to create unusual ideas, find original decisions, and move away from traditional schemes of thinking. The creative result must be original and unexpected. It must be different from the previous one, it must be adaptive and correspond to the different limitations of the given situation. Creativity is characterized also by the technical quality of the work and the use of the creative result by the society [11, p. 16]. There are 4 aspects in the study of creativity: creative process, result, person and environment. According to $G$. Wallas there are 4 stages of the creative process: preparation, incubation, illumination, verification [9, pp. 95-9]. Preparation stage is "hard, conscious, systematic, fruitless analysis of the problem". During the incubation stage the thinker does not consciously think about the problem. The third stage is the appearance of "happy idea", as Wallas calls. During the stage of verification the validity of the idea is tested and the idea receives its final form.

According to Wallas, in our everyday life these 4 stages overlap each other. For example, we can think about the first problem by preparing new information, while being in the incubation stage of another problem, and verifying the solution for the other problem.

We think that the 4-stage approach to the creative thinking can be used in order to have an influence on the unconscious processes during the stages of incubation and illumination by mindfulness meditation and to find out the opportunities of the creativity development. M. Beeman and J. Kounios call the illumination or insight stage as "aha moment" or "Eureka moment". It is the moment when a person suddenly guesses something he did not understand before, 
thinks about something familiar in a new way, or combines familiar things to get something new [5, p. 5].

E. Bouden and M. Beeman suggest that one should activate remote, weak, unconscious semantic network of alternative information in order to find not obvious solutions for the problem. Weak semantic activation, which is responsible for creating distant associations, occurs in the right hemisphere of the brain, while strong semantic activation occurs in the left hemisphere [3, p. 7]. Based on the electroencephalography data (EEG), M. Beeman and J. Kounios found that, when solving Compound Random Association Problems (CRAP) gamma brain waves become active 0.3 second prior to insight. And there is a sudden increase in alpha rhythm, a decrease in nervous activity in the the visual cortex in the right posterior parietal cortex 1.4-0.4 seconds before the insight based solution response [1].

Alpha brainwaves are associated with a state of relaxation, passive attention and deactivation of cortical areas. Increased alpha power measured over parietaloccipital cortex indicates idling or inhibition of visual cortex. Gamma brainwaves modulate perception, consciousness and concentration [1]. The study among novice meditators using electroencephalogram (EEG) shows that during the meditation alpha rhythms increase by $16 \%$ and gamma rhythms increase by $11 \%$ [8].

Research conducted by the same method among experienced meditators has shown that meditation, regardless of the type, activates the gamma rhythm. Meanwhile, the alpha rhythms activate during the vipassana meditation. During this meditation, the focus is on different parts of the body and sensations, thoughts and emotions without judging them [2].

This means that before insight, the brain tries to limit the visual deviation, thereby stimulating the creation of associations between distant semantic elements, enabling them to become conscious. In contrast, the decision based on the analysis is made in the background of neural activity in the visual cortex. In this case, the alpha rhythm activity is lower. Thus, during problem-solving process when a person wants to find distant associations, he should reduce nervous activity. In this case, the problem will be solved by insight, not by analysis. This is confirmed by A. Mednik's associative approach of creativity. According to him, creative thinking is based on associations, which are formed between thoughts. The farther the thoughts are, the more creative the thinking is [6].

The data obtained through scientific experiments allow assessing the role of meditation rationally in the process of obtaining a creative solution. The meditative state is the state between waking and sleep, the state of relaxation when the alpha rhythm is observed. In the meditative state the mental processes become slow. It helps to increase consciousness in the unconscious stage of incubation and to achieve insight. 
Mediation has three stages: relaxation, concentration, actual meditation state, the depth of which may vary depending on the experience, duration and terms [10, p.13]. Meditation is used as a mean to achieve mindfulness or a conscious state. Mindfulness is also called sudden awareness, presence or consciousness.

According to John Kabat-Zinn "mindfulness means paying attention in a particular way: on purpose, in the present moment, and nonjudgmentally. This kind of attention nurtures greater awareness, clarity, and acceptance of present moment realiy" $[4$, p.4].

The right hemisphere of the brain, which was suppressed by the left, during meditation, creates its own, complete, vivid images. During meditation, information from the outside world is temporarily not entered the brain. This allows freeing oneself from automatism, finding a new, alternative idea [10, p. 14].

D. Penman argues that mindfulness meditation promotes the development of divergent thinking, the emergence of a creative idea or insight, the courage to turn an idea into a product, and the development of personal qualities of creativity [7, p23]. Thus, mindfulness meditation helps to follow a path of weak semantic activation and the conscious state strengthens divergent thinking. It greatly helps a person to finally get out of the circle of thinking again and again with the same old way and find creative solution.

Based on the theoretical analysis survey, correlational and experimental research was done using the research methods of testing and experiment. The methods of diagnostics are the test by F. Williams for creativity assessment and for discovering the individual qualities of a creative person, Five Facet Mindfulness Questionnaire (FFMQ) by Ruth Baer.

The survey sample includes 30 young people, aged 18-35, with different spheres of activity. The level of creative thinking and the level of consciousness of young people have been studied by the above-mentioned methods of diagnostics.

According to the results of that study, the creative thinking of the subjects is generally above the average level. Although the subjects think quickly, the flexibility and elaboration of the thoughts is low. The least developed is the creative use of the words, the pictorial representation of the picture with the words.

The level of consciousness of young people is medium. Accordingly, it is relatively easy for them to get involved at the moment, not to act automatically, to notice and follow their external and internal experience - feelings, emotions, thoughts, to point them out, to describe them in words. It is more difficult for them to accept their inner experience without criticizing or pressuring them, just as it is more difficult to stay focused, not to go after thoughts, not to cling to thoughts.

After summarizing the testing data, a correlation research was done. As a result, we found interesting correlations between creative thinking and factors of consciousness. 
The correlation between creative thinking and level of consciousness shows that one is able to come up with new, diverse and unique ideas, when he is aware of his actions, is able to involve at the moment, does not act automatically and does not evaluate or judge his inner experience, is able to notice, point out his external and internal experience. (Figure 1).

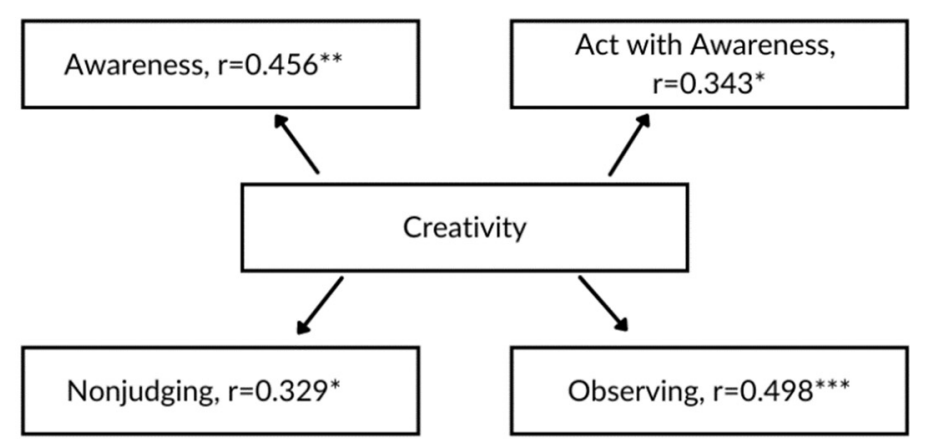

Figure 1. Correlations between creativity and awareness data, $p<0,05^{*}$, $p<0,01^{* *}, p<0,001^{* * *}$.

The correlation analysis shows that there is a high correlation between originality and observation $(0.463, p<0,001)$, which means that the more young people are able to express observation, follow and point out the inner experience, the more they are able to create new, unexpected, unique ideas. It is noteworthy that having a high level of awareness in general promotes emerging of unique thoughts and ideas $(0.385, p<0.01)$. The correlations between elaboration and observation $(0.333, p<0.05)$ as well as elaboration and consciousness $(0,329, p$ $<0,05$ ) indicate that the more young people can notice, trace and point out their inner and outer experience, the more they are able to be here and now, in the present, the more they are able to enrich and refine the idea and the thought, to make them more interesting and deep. In case of observation, they can also use the creative speech, give the idea smart names $(0.417, p<0.01)$.

Summarizing the results of the research, we can conclude that young people can offer unique, non-standard ideas, develop them, orient in difficult situations, look for alternatives, in case of observation, acceptance without criticism, conscious action, description of experience and general awareness.

Research data and theoretical analysis provided the basis for applying the meditation method in the development of creativity. For the experiment, we selected experimental and control groups from 30 subjects, based on the level of creative thinking. Seven of them were included in the experimental group on a voluntary basis. 
For the experimental group we conducted training for the development of creativity through mindfulness meditation. The duration of the training was 5 hours, an hour per day. During the training, the subjects were given problems which suppose creative solutions. Mindfulness meditation was used to get a creative solution and to develop creative thinking.

The training plan includes the following mindfulness meditations taken from "Mindfulness for Creativity" monograph by Danny Penman: Breathing, Voices and Thoughts, Flexibility, Insight. They are aimed at the development of creativity. We have chosen the mentioned mindfulness meditations, as their aim is the development of creativity. The training includes also creative problems, which check the fluency, flexibility, originality and elaboration of participants' thinking.

Retesting done at the end of the training showed that the average indicators of creative thinking (from 97 to 106), as well as the level of awareness become higher (from 129 to 138). The indicator of originality remained the same, the indicators of flexibility, elaboration and naming became higher. (Figure 2)

\section{Test for Creative Thinking: Average Indicators}

Before Training After training

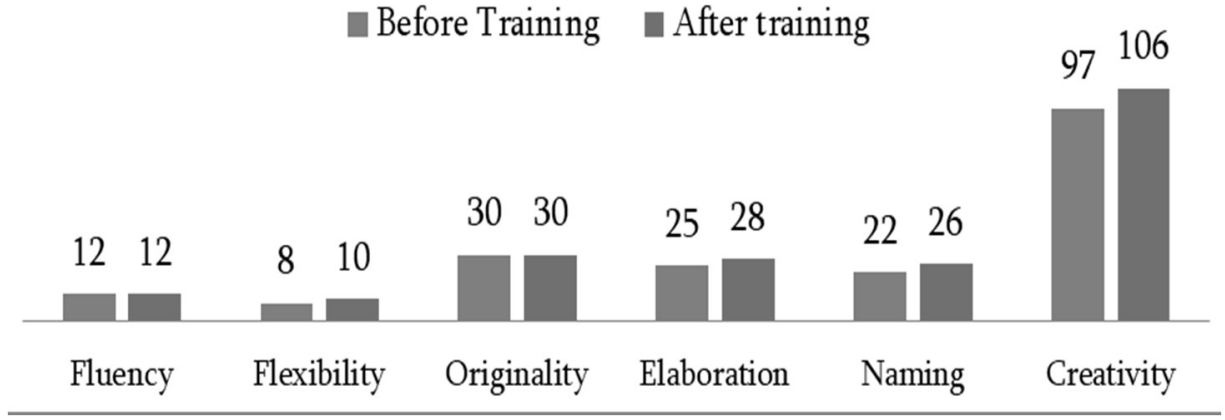

Figure 2. Average indicators of creative thinking before and after the training.

As a result of the re-testing of the subjects of the control group, no significant changes were registered between the creative thinking and the level of consciousness. Slight changes in the indicators of creative thinking have been registered. Some of the results have decreased, others have increased.

Thus, the experiment mainly confirmed the correlation between consciousness and its factors on one hand and creative thinking and its criteria on the other hand. As a result of the training, the participants developed their skill at elaboration, naming and creative thinking. Although the correlation analysis did not find a link between the flexibility and consciousness, the training showed an increase in flexibility, while originality which was correlated with the level of observation and consciousness, remained unchanged. 
As a result of the content analysis of the training, we can conclude that most of the answers given by the participants after the meditation were based on distant associations. They were unique, diverse, and comprehensive. Many answers had "creative flight" in solving problems.

This allows us to confirm our hypothesis: mindfulness meditation as a method of psychological self-regulation promotes the development of a person's creative thinking. We can conclude that the state of weak concentration resulting from meditation allows reaching distant associations and finding a creative solution from there. The conscious state contributes to the development of divergent thinking. The use of meditation in the incubation and illumination stages of the creative process promotes the development of a person's creative thinking, the emergence of creative insight and creative solution. Meditation raises the level of originality, flexibility, elaboration and creative thinking generally.

The results of the research provide a basis for continuing the study of creativity development, the trainings of mindfulness practices and their teaching, realizing new experiments in order to get more significant changes in creative thinking. New experiments may take into account changes in training terms, doing mindfulness meditation between training hours, the formation of mindfulness as a skill, and the teaching of the peculiarities of creative thinking.

\section{References}

1. Beeman J.M., Bowden E. M., Haberman J., Frymiare J. L., Arambel-Liu S., Greenblatt R., Reber P. J., Kounios J., Neural Activity When People Solve: Verbal Problems with Insight, PLoS Biology, April 2004, Volume 2, Issue 4, https://doi.org/10.1371/journal.pbio.0020097.

2. Braboszcz C., Rael Cahn B., Levy J., Fernandez M., Delorme A., Increased Gamma Brainwave Amplitude Compared to Control in Three Different Meditation Traditions, PLOS ONE, 2017, https://doi.org/10.1371/journal.pone.0170647.

3. Carpenter W., The Aha! Moment: The Science Behind Creative Insights, IntechOpen, 2019 http://dx.doi.org/10.5772/intechopen.84973 .

4. Kabat-Zinn J. Wherever You Go, There You are: Mindfulness Meditation in Everyday Life, Hyperion, N.Y., 280pp.

5. Kounios J., Beeman M. The Eureka Factor: Aha Moments, Creative Insight and the Brain, Random House, New York, 2015, 288pp.

6. Mednick S. A. The Associative Bases of the Creative Process, University of Michigan, Psychological Review, Vol. 69, No. 3, 1962, 220-232.

7. Penman D., Mindfulness for Creativity: Adapt, create and thrive in a frantic world, Piatkus, London, 2015, 224 pp. 
8. Stapletona P., Dispenzab J., McGillc S., Sabota D., Peachd M., Raynora D. Large effects of brief meditation intervention on EEG spectra in meditation novices, IBRO Reports, Volume 9, 2020, pp. 290-301, https://doi.org/10.1016/j.ibror.2020.10.006 .

9. Wallas G. The Art of Thoughts, Solis press, Kent, 2014, 392pp.

10. Каганов Л. Медитация-путь к себе, Кокон, Москва, 1990, 53 с.

11. Любарт Т., Муширу К., Торджман С., Зенасни Ф. Психология креативности, Когито-Центр, Москва, 2009, 215 с.

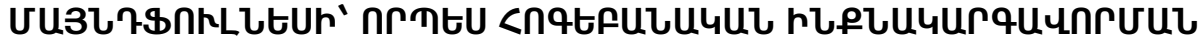

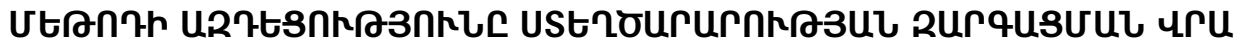

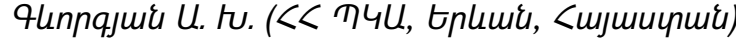

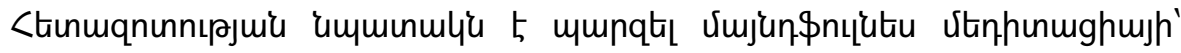

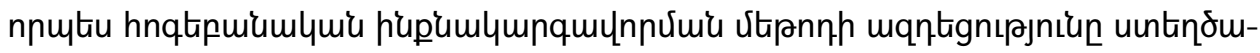

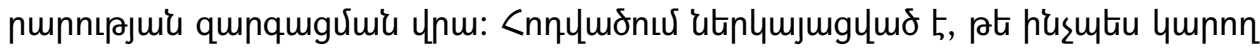

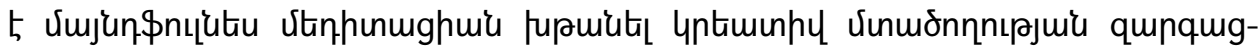

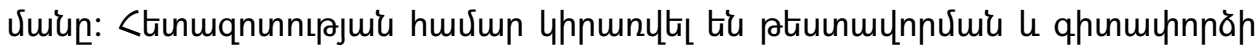

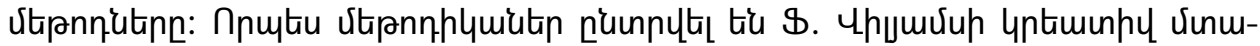

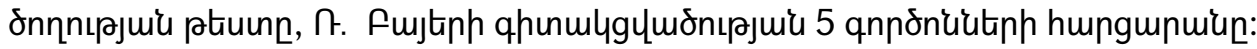

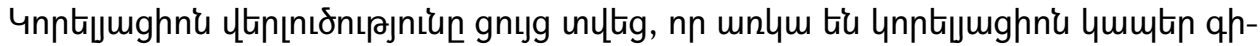

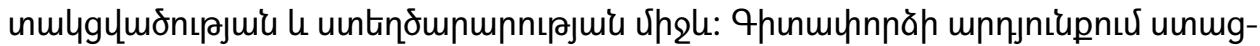

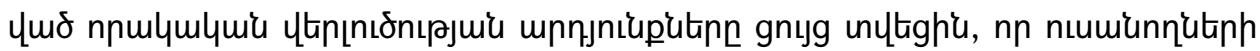

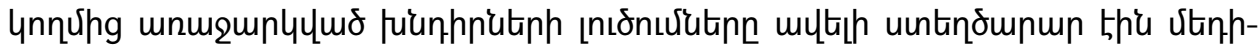

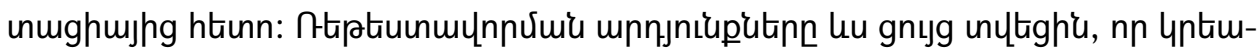

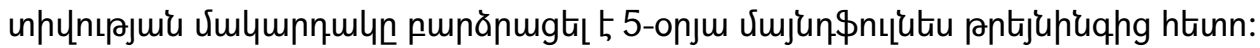

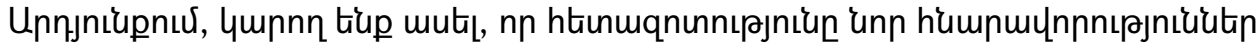

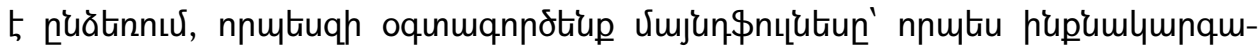

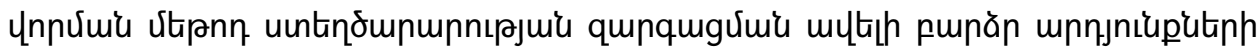
huukutent huvium:

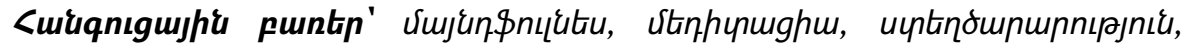

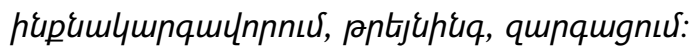

\section{ВЛИЯНИЕ МАЙНДФУЛНЕС КАК МЕТОД ПСИХОЛОГИЧЕСКОЙ САМОРЕГУЛЯЦИИ НА РАЗВИТИЕ ТВОРЧЕСКИХ СПОСОБНОСТЕЙ}

Геворгян А. Х. (АГУ РА, Ереван, Армения)

Цель исследования - выяснить влияние майндфулнес медитации как метода психологической саморегуляции на развитие креативности. В статье 
описывается, как майндфулнес медитация может способствовать развитию креативного мышления. Для исследования использовали методы тестирования и эксперимента. В качестве методик были выбраны тест Ф. Вильямса, который оценивает критерии креативного мышления, также 5-факторный опросник осознанности (Рут Баер). Корреляционный анализ показывает, что между уровнем осознанности и креативности существуют значительные связи.

В результате качественного анализа эксперимента выяснилось, что решения, предложенные студентами после медитации, были более креативными. Результаты повторного тестирования показали, что уровень креативности улучшился после 5-дневного тренинга майндфулнес. Исследование открывает новые перспективы для использовании майндфулнес медитации как метода психологической саморегуляции, чтобы получить более высокие результаты для развития креативности.

Ключевые слова: майндфулнес, медитация, креативность, саморегуляция, тренинг, развитие. 